\title{
Self-efficacy, soccer skills and the influence on students' learning experience
}

\author{
Ahmad Fahim Zulkifli, Pamela Kulinna \\ Mary Lou Fulton Teachers' College, Arizona State University, Phoenix, USA
}

\section{Summary}

Study aim: The purpose of this study was to evaluate the effects of a student centered curricular intervention on students' selfefficacy and soccer skills performance.

Materials and methods: One group of 25 mixed-gender students (ages 11-13) participated in this study of student centered soccer lessons twice per week (30 minutes) on a soccer field for three weeks at a Southwestern USA Middle School. The intervention was designed to engage students in the skill lessons by adopting a student-centered approach, and reciprocal/peer teaching of the soccer skills. Students' self-efficacy was assessed using the modified Traits Sport-Confidence Inventory. Soccer skill performance was assessed using previously validated skill tests. Further, students' perception of reciprocal teaching were gathered using exit slips. Data were analyzed using descriptive statistics and $t$-tests to explore pre/post differences.

Results: The students' skill performance slightly improved. Students' self-efficacy related to soccer skills was significantly higher at post-test. Students' positively perceived the opportunities to participate in student-centered lessons and the use reciprocal teaching styles to work together in skill development.

Conclusions: This study demonstrated that seventh-grade students could learn soccer skills, develop desirable perceptions and efficacy and improve their physical activity/sport participation levels as they engaged in student-centered teaching and learning.

\section{Keywords: Student-centered approach - Practice type - Reciprocal teaching}

\section{Introduction}

The rationale for this study came out of class observations at a local middle school in the Southwestern USA. The students (aged 11-13 years old) appeared to be uninterested in participating in physical activity/sport. The lessons observed were taught with technique and drills methods for learning sports skills. The lesson outcomes were not achieved as expected. These after-lunch physical activity sessions were also lacking in consistent reinforcement of the rules by the teacher. The focus of each activity was solely based on participation and learning was limited. Furthermore, the relationship between the teacher and students appeared to be limited. Further, there appeared to be limited cognitive and emotional engagement which can lead to students' disengagement from the activity. Thus, this project was designed to increase engagement in sport skills of these specific observed students in physical education.
Physical education was the only subject that was specifically stated in the law under the Education for All Handicapped Children Act (EAHCA) 1975 and categorized as a service rather than placement. Ideally, physical education was used as a platform to provide students with the chance to acquire and develop motor skills, build selfesteem, gain knowledge through physical activity, collaborate with peers as well as to participate in an enjoyable learning environment [10].

Despite the national efforts to emphasize physical education in schools, previous studies showed that programs were unsuccessful in promoting sufficient and consistent physical activity participation. According to Centers for Disease Control and Prevention [18], student transition from elementary to secondary schools contributes to this downward trend in participation in physical activity and physical education for girls and boys. This results in less time spent in physical activity as well as less time strengthening motor skills, movement forms, and character development through an active physical education learning environment. 
Several authors point to the secondary curriculum and its delivery as issues contributing to less participation in physical activity and physical education in the teenage years, as well as teaching methods in physical education that do not take individuals' experiences and capabilities into consideration (e.g., direct teaching styles). Ignoring these fundamental factors can lead to students' disengagement and socially construction of gender bias $[5,6]$.

\section{Student-centered approach}

The student-centered approach shifts some learning responsibility to the learners and allow them more ownership in the learning process. This approach encourages higher student involvement to inquire, speculate, reflect, analyze, and find solutions to challenges during physical activity [9].

In this method, the teacher can facilitate student learning through a combination of questions, challenges, scenarios, and modified learning activities to develop student creativity, lifelong learning pattern, and content knowledge [in this case of soccer] [19]. This two-way communication between teachers and students produces comfortable learning environment to practice and collaborate without fear of failure among students [9].

\section{Play-practice}

Play-practice is a concept that integrates blocked, random, and variable practice. The concept was chosen for this study due to its features which allow students to be good at sports, emphasizes a variety of practice formats, playing in teams or groups, and competing in evenly balanced competition. Additionally, play-practice also provides the students with more central roles in their learning as well as an authentic learning experience [20].

Using blocked practice periodically for short period during physical activity lessons helps student to correctly practice the techniques. Students practice the specific skill in a closed environment for short period before resuming modified game [30]. Meanwhile, random practice exposes students to different techniques to complete the skill which enhances the learning process [24]. This type of practice improves skill acquisition as Bernstein [1] explained that random practice required students to reconstruct the ideas and actions rather than memorizing the skill techniques. The variable practice type involves modifications of the learning environment without altering the content and learning process of the sports skills. Previous authors have supported the positive effects of variable practice which in their study children demonstrate refined movement adjustment to different settings when learning to throw [29]. This study used all of the play practice techniques. In teaching skill lessons, there are many different teaching styles that can be used. This study adopted the reciprocal teaching style for the soccer unit.

\section{Reciprocal teaching}

Reciprocal teaching is associated with a partnership design whereby students work together in pairs or a small group toward achieving specific objectives and goals [2]. It emphasizes social skills; students are encouraged to learn together, discuss, and make decisions together on issues and provide each other feedback. This style has helped nurture quality traits such as tolerance, critical thinking, and leadership in students [2].

Johnson and Ward [13] studied the reciprocal teaching style as compared to a teacher-directed style over 20 days of a striking unit with girls. They found that reciprocal teaching led students to perform fewer trials of a higher quality regarding accuracy as well as higher percentages of correct technique used for both high-skilled and lowskilled girls. Furthermore, with teacher's guidance, the students were capable of analyzing their peers' performance with a $90 \%$ accuracy rate. The reciprocal teaching style has also been reported to not alter the organizational time for teachers [13].

One previous study of girls' soccer skills performance and self-efficacy founded statistically significant increases in skill development and efficacy achieved within a 5 week (3 days/week, 45 mins/lesson) period, the authors did not clarify the situation regarding the students' experience, and girls voluntarily participated in the study [3]. In addition, Vera, Alvarez, and Medina [30] studied the influence of practice type on students' acquisition, retention, and transfer of soccer skills. Authors suggested that the application of the various type of practice did not apply across situations and more studies are needed on practice types across contexts. A third study, of an after-school sports program found that emphasizing solely on sportbased physical activity was not sufficient to change students' behavior related to physical activity/sport participation. Authors suggested that future studies should combine skill instruction with psychosocial strategies to promote learning across all domain (psychomotor, cognitive, \& affective) [11]. Further studies are also needed to learn more about engagement by students in secondary skill development in physical education programs.

\section{Purpose}

The current study builds on these previous studies to determine if a group of girls and boys with voluntary participation in physical education would benefit from a unit designed to influence all domain areas, that is be student centered (affective), included a variety of practice types (psychomotor), and used reciprocal teaching methods (cognitive) for soccer skills. Therefore, the following research questions were being addressed in this study: (1) does the intervention improve students' self-efficacy related to learning soccer skills?, (2) does the intervention influence students' perceptions of skill development 
in physical education?, and (3) does the intervention increase students' abilities to perform fundamental soccer skills (i.e., passing, shooting, dribbling)?.

\section{Material and methods}

\section{Participants}

The participants of this study were seventh grade students, there were total of 25 (16 boys and 9 girls) with an age range of 11-13 years old. The majority of participants reported a Caucasian ethnic background with two reporting Hispanic, and one Asian-American. The school is predominantly (83\%) Caucasian, with also students reporting (18\%) Hispanic, (8.7\%) Asian and (4.1\%) African American heritages [23]. Most of the participants orally reported limited experience and skill in soccer.

\section{Setting}

The Excellent Learning Academy (pseudonym) was located in a large suburban area in the Southwestern USA and had a minority of students in the Reduced or Free Lunch Initiative Program (17\%). There were 435 students enrolled in the school. There were more female students enrolled (53\%) than males (47\%).

The school's outdoor field was the main area used to implement the intervention. The after-lunch physical education sessions were 30 minutes long. The rules, equipment, and learning environment were modified to help students learn and achieve a higher rate of success during practice.

\section{Study design and procedures}

The intervention involved a student-centered approach, varying the practice type, and using reciprocal teaching for learning soccer skills in an after-lunch physical education session lasting for three weeks ( 6 class sessions) between in February and March 2017. This study primarily focused on accentuating participants' roles during skill development and assessing outcomes on their self-efficacy related to soccer, such as skill executions, and decision-making. Participants were given more opportunity to explore possible options during gameplay, make a collective decision, and dictate their own learning sessions under the teacher's supervision. Additionally, teacher initiating situationalrelated discussions during games also helped students to improve their linking between understanding and actions.

The intervention altered the type of practice (from traditional drills). They included play-practice where the equipment, rules, and learning environment (i.e., bright soccer ball, no high ball above waist, small diamond shape playing area) were modified according to the participants' current level of abilities in soccer, to use age-appropriate activities, and to inform participants of specific learning objectives. Instructional methods used during the intervention were reciprocal teaching. Participants' comprehension and skill acquisitions on fundamental soccer techniques were assessed using skill tests and assessing their perceptions using exit slips.

Before the interventions, participants were introduced to the team covenant system and its purposes to their learning. According to Ronglien [21], the team covenant system refers to a collection of statements that participants collectively accepted to respect and adhere throughout the study. This system helps the researcher to established routines and promote positive attitudes among them.

Throughout this study, the teacher adopted the roles of a facilitator and task delegator; the instructions were minimal, and participants were given more time to practice soccer in an authentic environment. The teacher's roles included organizing the skill tests for specific skills, initiating discussion with participants related to their physical activity and skill practice, as well as giving functional feedback during practice. Although they were given more responsibilities in their learning experiences, the teacher was expected to intervene when problems arose either physically or emotionally [17]. Institutional Review Board approval was obtained from the University and school. Parents and the teacher provided consent, while students gave assent for participation.

The first author designed the intervention and was present at the school during all class sessions. The researchers also noted the day of the intervention in a log with daily notes. The intervention focus on soccer skills and game sense within modified learning environment. Every session was ended with competitive mini-game to help students practice and applied what they have learned to a game situation. Data were collected at the beginning and end of study which included students' perceived self-efficacy on soccer skills using TSCI, entry and exit slips related to reciprocal teaching, and soccer skill tests $[7,30]$.

\section{Instruments}

Instruments that have shown that they produce reliable and valid scores were used for this study. These included the Traits Sport-Confidence Inventory (TSCI), soccer skills competency tests and entry and exit slips on soccer skill perceptions.

The Traits Sport-Confidence Inventory (TSCI). This instrument contains 13 questions with no subscale components and utilizes a 9-point Likert-like scale ranging from low to high. Specifically, it was used to explore participants' feelings and degree of certainty that they were capable of learning and performing soccer skills [27]. Participants were asked to self-assess their sense of competence on various aspects of soccer (i.e., skill executions, making decisions). The instrument developer 
supported the TSCI inventory's validity and reliability, and used a similar sample of youth [27, 28]. The selfefficacy score was obtained by adding up scores for the 13 items. General confidence scores of 13 to 39 indicate low-level confidence and scores of 91 to 117 represent a high level of self-confidence. Meanwhile, the scores obtained in between those levels are considered moderate levels of self-confidence [25].

Soccer skills competency tests. Skill tests were used to assess participants' fundamental soccer skills in ballkicking, dribbling, and passing movements. The procedures were adopted from the previous study on practice condition effects on students' learning soccer skills [30]. With regards to ball-kicking, participants were given five attempts to make a shot using a regulation soccer ball toward set targets with their dominant foot. The target was placed on the ground five meters away from the ball. Specifically, the target was $100 \mathrm{~cm}$ long $\times 20 \mathrm{~cm}$ high and be divided into five linear scoring zones of $20 \mathrm{~cm} \times 20 \mathrm{~cm}$. The central zone represents five points, other zones on either side indicate three points and the two outer zones worth one point. The target was fastened to the wall in a horizontal position with its bottom edge touching the ground [30].

Ball-dribbling skill test involved participants moving past cones with a regulation soccer ball. The test was conducted on a 10 meters course ( $5 \mathrm{~m}$ out and $5 \mathrm{~m}$ back) with the cones set one meter apart [30]. Furthermore, participants were required to dribble the ball to the right and left of each successive cones. Time started when they crossed the line at the beginning of the test and stopped once they cross the line again at the end of the test [30].

Additionally, the passing and trapping skill test involved participants standing two meters away from the wall. Once signaled, participants started passing the ball to the wall with sufficient force which led the ball to bounce back and trap the ball from their starting position. They were given 30 seconds to complete as many successful passes and traps of the ball as possible [7]. They were encouraged to utilize both feet to complete the test. Nonetheless, participants were not penalized or given bonus point if they decided not to switch feet during the test. Essentially, the ball must come to complete rest at starting position before attempting another pass [7].

Entry and exit slips on perceptions. The entry and exit slips were given to participants as part of the preand-post assessments. The slip contained seven questions (i.e., "does reciprocal teaching involve everyone?") that required participants to provide short answers and used a scale (i.e., 0 - less likely and 5 - very likely). Feedback from the participants related to their perceptions of reciprocal teaching and its influence toward their learning process. Besides that, it was used to assess participants' ability to relate what they have learned in the sessions with other aspects of their lives (i.e., academic, social) in class discussions.

Several authors have recommended the used of entry and exit slips to promote participants' learning by developing in-depth knowledge in soccer through the combination of reading, writing the contents, and skill practice [12]. The information gained allowed the researchers to make a comparison on reciprocal teaching between pre-and-post interventions. Results from the intervention helped provide changes to teaching the soccer unit at the school.

\section{Data analysis}

Descriptive statistics, that is, means, standard deviations (SD), and percentages, were calculated for variable assessed in this study (self-efficacy, soccer skills, entry and exit slips) [16]. $t$-tests were used to look at the differences (pre-and-post intervention scores) on participants' self-efficacy and soccer skills [26]. A Bonferroni adjustment was made to the $p$ value required for significance since more than one $t$-test was performed on the data set (i.e., alpha/\# of comparisons or a $p=0.02$ for significance).

Additionally, bar graphs were used to visually compare the pre-and-post differences qualitatively. Bar graphs can be used to determine the significance of behavioural changes among participants, behavior interpretations, and offer visual feedback to readers [4].

\section{Results}

After the exclusion of 4 participants (i.e., missing pretest or post-test values), participants consisted of 21 students who were enrolled in the intervention study throughout the three-week time frame.

\section{Participants' confidence level}

The effect of the intervention on participants' self-efficacy, is shown in Figure 1 below, showed small increases of approximately $0.5-1.9 \%$ with the most significant improvement of $1.9 \%$ found in the performance descriptor, "ability to make a critical decision during practice or soccer games." Participants' post-test scores for items 8 and 13 , found in the performance descriptor "ability to consistently successful during practice or soccer games" and "adapting to a different type of practice and soccer game situations" were documented at an average success rate of $0.5 \%$ respectively. This was observed to be a small increase from the pre-test result. Participants had significantly greater efficacy $(\mathrm{M}=7.26, \mathrm{SD}=1.07)$ at the posttest than they did in the pre-test $(\mathrm{M}=6.30, \mathrm{SD}=1.24)$. The $t$-test scores related to self-efficacy was $t(20)=-3.56$, $p<0.02$ ). 


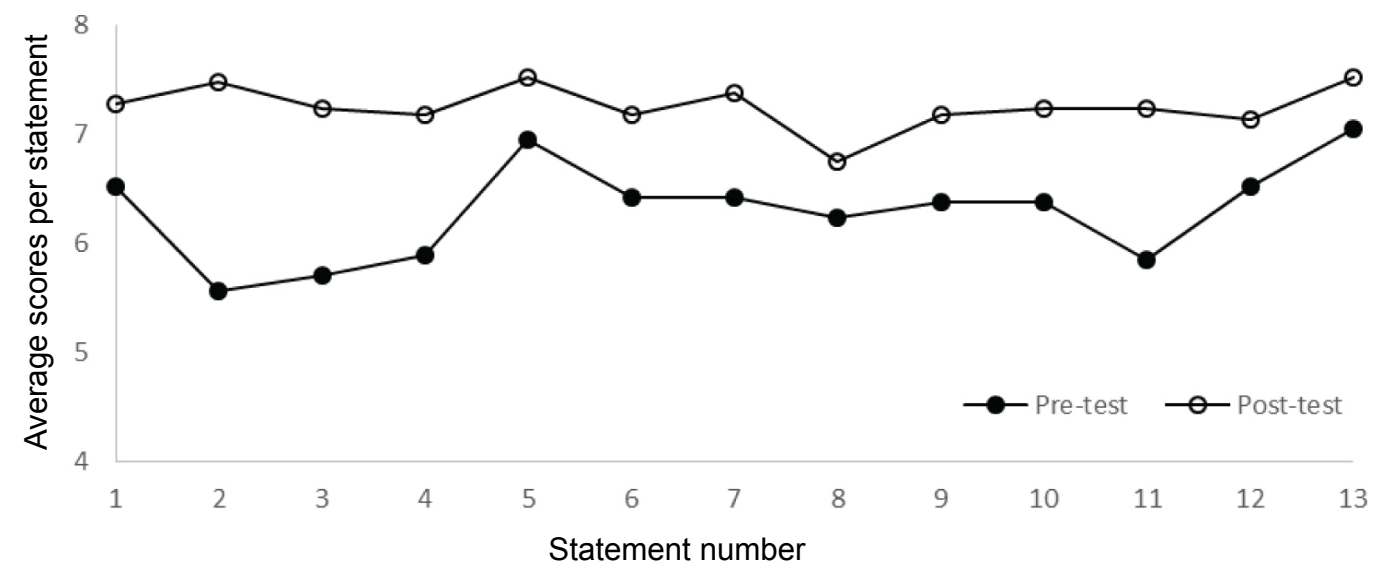

Fig. 1. Mean self-efficacy level on soccer skills performance across pre-and-post intervention

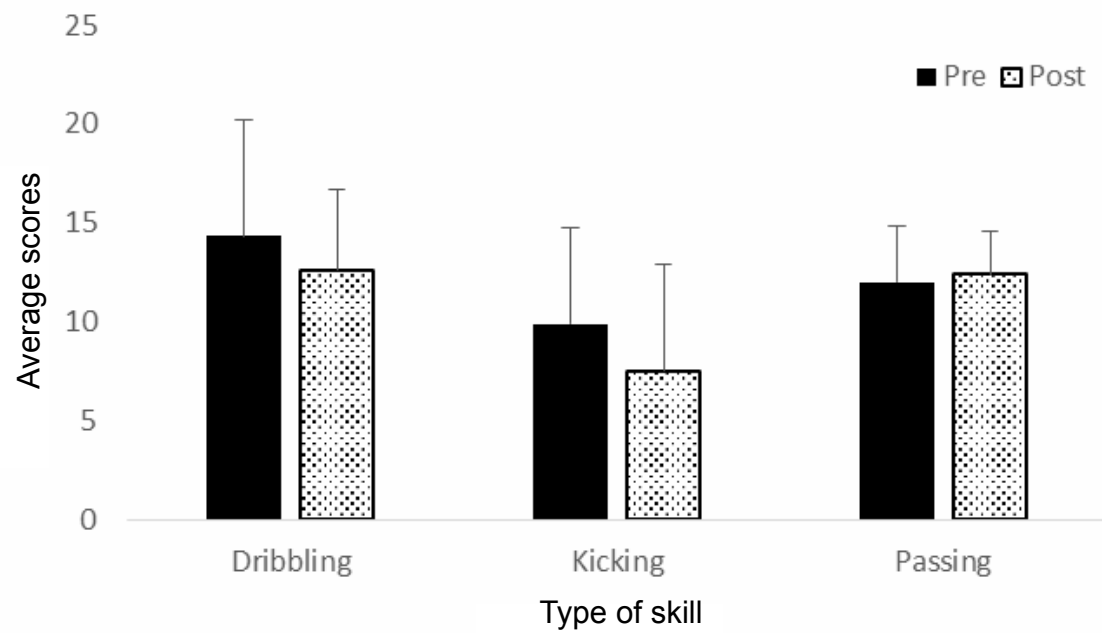

Fig. 2. Mean scores of students' soccer skills performance across pre-and-post intervention

\section{Soccer skill performance}

Participants in this study had low soccer skills test results both pre-and-post assessments. Participants had slightly lower scores $(\mathrm{M}=12.6, \mathrm{SD}=4.1)$ and $(\mathrm{M}=7.5$, $\mathrm{SD}=5.3$ ) on dribbling and ball-kicking skills respectively on post-test compared with scores of $(\mathrm{M}=14.3, \mathrm{SD}=5.9)$ and $(\mathrm{M}=9.9, \mathrm{SD}=4.9)$ on pre-test. They did improve slightly on passing skills with $(\mathrm{M}=12.4, \mathrm{SD}=2.2)$ on post-test compared with score of $(\mathrm{M}=12.0, \mathrm{SD}=2.8)$ on pre-test. The $t$-test score for the passing were $t(20)=-0.76$, $p<0.05)$.

\section{Reciprocal teaching slips}

Descriptive statistics results for the reciprocal teaching exit slips scores across pre-and-post intervention are presented in Table 1 . The $t$-test for the pre-test and posttest reciprocal teaching slips were $t(20)=-5.30, p<0.01)$. Participants had a mean improvement in perceptions of reciprocal teaching of $4.2(0.012 \%)$.
Table 1. Mean, standard deviation, and $t$-test for the reciprocal teaching slips

\begin{tabular}{|c|c|c|c|c|}
\hline \multicolumn{2}{|c|}{ Pre } & \multicolumn{2}{|c|}{ Post } & \multirow{2}{*}{$t$-test } \\
\hline Mean & SD & Mean & SD & \\
\hline 3.03 & 0.70 & 4.22 & 0.65 & -5.30 \\
\hline
\end{tabular}

\section{Discussion}

Henninger and Pagnano Richardson [9] explained that student-centered learning is essential and provides individuals with skills to succeed in learning. Despite its importance, many teachers of all grade level still resist or are hesitant to try student-centered learning or to change their teaching, classroom organization, or student-engagement types [8, 14]. This study showed that through changing to more student-centered learning, students improved their perception 
toward reciprocal teaching, students increased their self efficacy toward soccer and there were some positive skill changes for passing skills (although not quite significant in passing and not significant in the other skill areas).

According to Prusak and Darst [20], to maximize teaching and learning, students should be provided with high ownership of learning experiences. The currrent study was designed with these recommendations in mind. In each session, participants were given a chance to engage in learning through modified game-based approach, practice specific techniques and to play competitive modified soccer game to promote active involvement. This student-centered approach may have been one reason for the improvement of participants' self-confidence from this study. Above all, activities that promote higher learning ownership and are appropriately challenging to the students have been shown to improve student engagement and self-confidence, which can aid in learning [19].

Although Chatzopoulos et al., [3] found that girls' soccer skills performance and self-efficacy can be improved within five week (3 days/week, 45 minutes/lesson) period, this study was not able to replicate their result in term of skills performance (with only passing skill performance improvements), perhaps due to shorter lessons and a shorter intervention time. As there were only six sessions (2 days/ week) lasting for three weeks in this study compared to 15 sessions (3 days/week) lasting for five weeks in the previous study; this could be a factor that contributed toward a lack of consistent skills improvement. Additionally, there was also less contact time with the participants in this study (30 minutes/session) compared to their study (45 minutes/ session) resulting in fewer intervention effects.

According to Rovegno [22], teacher's inexperience in both classroom management and teaching soccer might be the most important mediating factor that influences individual skill performance. A lack of sufficient feedback (or content knowledge or planning) regarding skill performance may have played a role in the findings for this study. The teacher may have ignored the connections and progression across sports skills which could hinder student learning outcomes [15].

\section{Implication for practice}

Results from this study are valuable for teachers in their planning and management of physical education. Focus on students' learning as the primary goal, teachers can always modify their session on aspects such as rules, playing area, and equipment according to their students' capabilities and needs. Modification promotes active students involvement, enhance learning, and effective practice while preserving the authenticity of students' learning experience. This appeared to have promoted positive perceptions of ability (self-efficacy) and of the reciprocal teaching style. Nonetheless, the results of this study stress that more time for students to learn and practice was needed to improve their sports skill performance. Similarly, teacher's encouragement, along with prompt, and meaningful feedback are essential to cultivating intrinsic motivation within students to achieve success in physical education. A couple of limitations to the study included a short study duration, lack of a comparison group and small sample size.

\section{Conclusion}

This study provides teachers with an innovative strategy (student-centered learning, various practice structures and reciprocal teaching) to promote students' engagement and collaboration through sport that leads to learning outcomes. This study demonstrated that seventh-grade students could learn soccer skills, develop desirable perceptions and efficacy and improve their physical activity/sport participation levels as they engaged in student-centered teaching and learning. The student-centered approach can aid in increasing students' sports participation and may influence students' decision-making on future sport/physical activity participation.

\section{Conflict of interest: Authors state no conflict of interest.}

\section{References}

1. Bernstein N. (1967) The coordination and regulation of movement. New York: Pergamon.

2. Byra M., Marks M. (1993) The effect of two pairing techniques on specific feedback and comfort levels of learners in the reciprocal style of teaching. Journal of Teaching in Physical Education, 12(3): 286-300.

3. Chatzopoulos D., Drakou A., Kotzamanidou M., Tsorbatzoudis H. (2006) Girls's soccer performance and motivation: Games vs technique approach. Perceptual and Motor Skills, 103: 463-470.

4. Cooper J.O., Heron T.E., Heward W.L. (2007) Applied Behavior Analysis ( $2^{\text {nd }}$ ed.). Upper Saddle River, NJ: Pearson/Merrill-Prentice Hall.

5. Ennis C.D., Cothran D.J., Davidson K.S., Loftus S.J., Owens L., Swanson L., Hopsicker P. (1997) Implementing a curriculum within a context of fear and disengagement. J. Teach. Phys. Educ., 17(1): 52-71.

6. Flintoff A., Scraton S. (2001) Stepping into active leisure? Young women's perception of active lifestyles and their experiences of school physical education. Sport Educ. Soc., 6(1): 5-22.

7. Frankl D. (2014) Soccer skills instruction and assessment. Retrieved from http://kidsfirstsoccer.com/testing. html. 
8. Glotova O.N., Hastie P.A. (2014) Learning to teach sport education in Russia: Factors affecting model understanding and intentions to teach. Sport Educ. Soci., 19(8): 1072-1088.

9. Henninger M.L., Richardson K.P. (2016) Engaging students in quality games. Strategies, 29(3): 3-9.

10. Hill L. (2007) Friendship, physicality, and physical education: An exploration of the social and embodied dynamics of girls' physical education experiences. Sport Educ. Soci., 12(3): 317-336.

11. Huang C., Gao Z., Hannon C.J., Schultz B., Newton M., Jenson W. (2012) Impact of an after-school physical activity program on youth's physical activity correlates and behavior. J. Res. Health, Phys. Educ., Recreat. Sport Dance, 7(1): 18-23.

12. James R.A., Bullock K. (2015) Integrating the English Language Arts Common Core state standards into physical education. J. Phys. Educ. Recreat. Dance, 86(3): 25-31.

13. Johnson M., Ward P. (2001) Effects of classwide peer tutoring on correct performance of striking skills in $3^{\text {rd }}$ grade physical education. J. Teach. Phys. Educ., 20: 247-263.

14. McCaughtry N., Sofo S., Rovegno I., Curtner-Smith M. (2004) Learning to teach sport education: Misunderstandings, pedagogical difficulties, and resistance. Eur. Phys. Educ. Rev., 10(2): 135-155. DOI: 10.1177/1356336X04044068.

15. McMahon E., MacPhail A. (2007) Learning to teach sport education: The experiences of a pre-service teacher. Eur. Phys. Educ. Rev., 13(2): 229-246.

16. Mills G.E. (2014) Action research: A guide for the teacher researcher ( $5^{\text {th }}$ ed.). Boston, MA: Pearson.

17. Mosston M., Ashworth S. (1990) The spectrum of teaching styles: From command to discovery. New York: Longman.

18. Obesity prevalence map year (2014) Retrieved from http://www.cdc.gov/obesity/data/prevalence-maps.html.

19. Pagnano Richardson K., Henninger M.L. (2010) What do your students really know about game play? Using game play scenarios to go beyond the traditional written test. Strategies, 24(2): 15-18.
20. Prusak K., Darst P.W. (2000) Teaching strategies and game modifications to promote maximum participation in middle school physical education. Teaching Elementary Physical Education, 11(3): 18-23.

21. Ronglien L. (2016) Developing a team covenant. Retrieved from https://www.breakthroughbasketball.com/coaching/team-covenant.html.

22. Rovegno I. (1998) The development of in-service teachers' knowledge of a constructivist approach to physical education: Teaching beyond activities. Res. Q. Exerc. Sport, 69: 147-162.

23. School Digger.com (2017) Retrieved from http://www. schooldigger.com/go/AZ/schools.

24. Sherwood D.E., Lee T.D. (2003) Schema theory: Critical review and implication for the role of cognition in a new theory of motor learning. Res. Q. Exerc.d Sport, 74: 376-382.

25. Soltani H., Reddy K.S., Hojati Z. (2013) State and trait self confidence among elite and non-elite volleyball players in Iran. Adv. Environ. Biol., 7(2): 283-287.

26. Trochim W.M.K. (2006) The $t$-test. Retrieved from http:// socialresearchmethods.net/kb/stat_t.php.

27. Vealey R.S. (1986) Conceptualization of sport-confidence and competitive orientation: Preliminary investigation and instrument development. J. Sport Psychol., 8: 221-246.

28. Vealey R.S. (1988) Sport-confidence and competitive orientation: An addendum on scoring procedures and gender differences. J. Sport Exerc. Psychol., 10: 471-478.

29. Vera J.G., Montilla M.M. (2003) Practice schedule and acquisition, retention and transfer of a throwing task in 6-year-old children. Percept. Mot. Skills, 96: 1015-1024.

30. Vera J.G., Alvarez J.C.B., Medina M.M. (2008) Effects of different practice conditions on acquisition, retention and transfer of soccer skills by 9-year old schoolchildren. Percept. Mot. Skills, 106: 447-460.

\section{Received 25.09.2017 \\ Accepted 04.01.2018}

(C) University of Physical Education, Warsaw, Poland 